\title{
Sorvetes de chocolate simbiótico de baixa caloria: análise tempo-intensidade múltipla e estudo de preferência
}

\author{
Chocolate ice cream symbiotic low calorie: multiple \\ time-intensity analysis and preference study
}

\author{
Juliana Ferraz Peres', Helena Maria Andre Bolini* (1) \\ ${ }^{1}$ Universidade Estadual de Campinas (UNICAMP), Faculdade de Engenharia de Alimentos, Laboratório de Ciência \\ Sensorial e Estudos de Consumidor, Campinas/SP - Brasil \\ ${ }^{*}$ Corresponding Author: Helena Maria Andre Bolini, Universidade Estadual de Campinas (UNICAMP), Faculdade \\ de Engenharia de Alimentos, Laboratório de Ciência Sensorial e Estudos de Consumidor, Rua Monteiro Lobato, 80, \\ CEP: 13083-970, Campinas/SP - Brasil, e-mail: hellini@unicamp.br
}

Cite as: Peres, J. F., \& Bolini, H. M. A. (2020). Chocolate ice cream symbiotic low calorie: multiple time-intensity analysis and preference study. Brazilian Journal of Food Technology, 23, e2019108. https://doi.org/10.1590/19816723.10819

\begin{abstract}
Resumo
O sorvete é um produto amplamente consumido e aceito pela população mundial, e, por essa razão, é de grande importância a busca por formulações que possam ser menos calóricas, especialmente com redução ou ausência de sacarose. A determinação do perfil sensorial tempo-intensidade múltiplo (também denominado perfil sensorial dinâmico), associada ao estudo de aceitação, pode ser de grande importância para direcionar estudos e obter informações que possam contribuir com a obtenção de conhecimentos para a indústria de alimentos sobre mudanças de ingredientes e melhoria da qualidade sensorial. O objetivo do presente estudo foi estudar diferentes formulações de sorvetes de chocolate simbiótico, sendo uma adoçada com sacarose e outras sete adoçadas com diferentes edulcorantes (aspartame, sucralose, neotame e estévia com 60\%, 80\%, 95\% e 97\% de rebaudiosídeo A), por meio da aplicação de análise tempo-intensidade múltipla, análise de aceitação e verificação da influência da presença da inulina, do L. acidophilus e dos edulcorantes em características físico-químicas do produto. As amostras que apresentaram maior aceitação foram adoçadas com sacarose e sucralose, seguidas por estévia com $95 \%$ e $97 \%$ de rebaudiosídeo A. Por meio da análise do mapa interno de preferência, foi observada a importância pronunciada do sabor na aceitação das amostras. O edulcorante que possibilitou a obtenção do sorvete de chocolate de baixa caloria simbiótico, sem diferença significativa com o produto adoçado com sacarose em perfil de doçura, amargor e sabor de leite, bem como em aceitação, foi a sucralose. Os sorvetes de aceitação inferior foram adoçados com aspartame, neotame e estévia, provavelmente em razão do gosto amargo mais intenso e com maior tempo de duração $(p<0,05)$. A Os sorvetes com inulina em sua formulação apresentaram derretimento mais lento quando comparados à amostra sem inulina e formulada com sacarose.
\end{abstract}

Palavras-chave: Aceitação; Sorvete; Edulcorantes; Mapa externo de preferência; Perfil sensorial dinâmico. 


\begin{abstract}
Ice cream is a widely consumed and accepted by the world population. It is very important searching for less caloric formulations, especially with reduction or absence of sucrose. The determination of the multiple time-intensity sensory profile (also denominated dynamic sensory profile) associated to the acceptance study can be relevant to guide studies and obtain information to contribute for knowledge related to the food industry, especially concerning the ingredients changes and improvement of sensorial quality. The objective of the present work was to analyse different formulations of symbiotic chocolate ice cream, one sweetened with sucrose and seven sweetened with different sweeteners (aspartame, sucralose, neotame and stevia 60\%, 80\%, 95\% and 97\% rebaudioside A, respectively) with application of multiple time-intensity analysis, study of acceptance and verification of influence about presence of inulin, L. acidophilus and sweeteners, on the physical-chemical characteristics of the product. The samples sweetened with sucrose and sucralose showed the highest acceptance, followed by stevia with $95 \%$ and $97 \%$ rebaudioside $\mathrm{A}$...The internal preference map showed the flavour importance in the samples acceptance. The sucralose was the sweetener that produced a chocolate ice-cream symbiotic and low-calorie that presented no significant difference in relation to the traditional one (sweetened with sucrose) in relation to sweetness, bitterness and milk flavour time-intensity profile as well in relation to the acceptance $(p>0.05)$ The samples with lower acceptance was sweetened with aspartame, neotame and stevia probably for the presence of higher intensity and duration time of bitter taste $(p<0.05)$. The ice cream with inulin presented slower melting rate when compared to the sample with sucrose and inulin free.
\end{abstract}

Keywords: Acceptance; Ice cream; Sweeteners; External preference map; Dynamic sensory profile.

\title{
1 Introdução
}

O sorvete é um produto muito consumido no mundo inteiro. Muitas propostas de formulações têm surgido para obtenção de sorvetes sensorialmente aceitos e com menos calorias e mais saudáveis (Mintel, 2015).

Os sorvetes são classificados de acordo com a quantidade de gorduras e sólidos totais que apresentam, são eles: Ice Cream (mínimo 10\% de gordura e 20\% de sólidos totais); Ice Milk (2\% a 7\% de gordura e $11 \%$ de extrato seco, os sólidos não gordurosos); os Sherbet, atualmente conhecidos como "sorbets", são os sorvetes à base de fruta e água (Mosquim, 1999; Instituto de Laticínios Cândido Tostes, 2002).

O Brasil encontra-se na sexta posição mundial em volume de mercado de sorvetes. Os cincos primeiros são China, Estados Unidos, Rússia, Japão e Alemanha. Em relação ao consumo, a Nova Zelândia é a maior consumidora de sorvetes, com 28,3 L/habitante/anualmente, seguida dos EUA $(20,8)$, Austrália $(18,1)$, Suécia $(14,3)$ e Finlândia $(14,3)$. No Brasil, o consumo anual por habitante foi de seis litros, o que faz com que a indústria trabalhe em busca de mudanças culturais no consumidor brasileiro, fazendo com que o consumo de sorvetes ocorra durante o ano todo, não somente no verão (Associação Brasileira das Indústrias e do Setor de Sorvetes, 2016).

O investimento em mudanças de sabores e nas formulações vem agradando o consumidor (Sanders \& Marco, 2010). A substituição de gorduras hidrogenadas por gorduras de origem láctea, como é o caso do creme de leite, a adição de aditivos funcionais, como é o caso da Inulina e do Lactobacillus acidophilus, além da substituição da sacarose por edulcorantes naturais, como a Estévia, e sintéticos, como aspartame, neotame e sucralose, agregam valor ao produto e o torna mais atraente ao consumidor.

Os prebióticos são definidos como ingredientes não digeríveis, podendo ser desde as fibras dietéticas (fruto-oligossacarídeo, inulina e galacto-ologossacarídeo) até os compostos fenólicos e o xilitol, que afetam beneficamente o hospedeiro agindo seletivamente, estimulando o crescimento de bactérias benéficas no cólon intestinal ou em outros lugares do hospedeiro, como a boca, melhorando assim a saúde do indivíduo (Gibson et al., 2017). A presença da inulina e do L. acidophilus torna o sorvete um alimento simbiótico, que consiste na combinação dos prebióticos com os probióticos, agindo em sinergismo (Gibson \& Roberfroid, 1995; Cruz et al., 2010). 
Os principais substitutos de sacarose nos produtos são os edulcorantes, sendo que os mais habitualmente utilizados são os sintéticos, entre eles o aspartame, a sucralose e o neotame. Porém, a estévia vem ganhando espaço e sendo muito estudada e utilizada em produtos com substituição total ou parcial de sacarose, pois se trata de um edulcorante natural, uma vertente bem vista pelos consumidores (Mello et al., 2010).

A análise sensorial é uma ferramenta de extrema importância para o desenvolvimento de um novo produto ou o aperfeiçoamento de um já existente no mercado, pois é a única técnica para mensurar a aceitação de produtos pelos consumidores (Umbelino, 2005).

A análise tempo-intensidade é um prolongamento da análise descritiva clássica, uma vez que possibilita mensurar a intensidade de qualquer característica sensorial (especialmente gostos, sabores e texturas) em função do tempo, ou seja, durante o consumo do alimento, desde o início da percepção até a completa extinção, sendo considerada como uma análise dinâmica e avançada (Dijksterhuis \& Piggott, 2000; American Society for Testing and Materials, 2017).

Palazzo \& Bolini (2009), em pesquisa realizada com gelatinas sabor framboesa, adoçadas com diferentes edulcorantes, representaram os resultados das curvas tempo-intensidade de doçura, amargor, sabor framboesa e acidez, sobrepostas num mesmo gráfico. Os autores denominaram a forma de representação como análise tempo-intensidade múltipla.

Em norma oficial para análise tempo-intensidade da American Society for Testing and Materials (2017), a análise tempo-intensidade múltipla proposta por Palazzo \& Bolini (2009) é citada como uma forma de sumarização da modelagem das formas das curvas tempo-intensidade obtidas, conforme indicado nos estudos publicados por Dijksterhuis \& Eilers (1997) e por Overbosch (1986), sendo uma técnica de representação dos resultados de descritores (analisados de forma independente) sobreposts, num único gráfico, por amostra.

Em literatura científica, são encontrados resultados de pesquisas que aplicaram a análise tempo-intensidade múltipla em estudos sensoriais dinâmicos de diferentes produtos alimentícios, como formulação de chocolate amargo adoçado com estévia em diferentes porcentagens de rebaudiosídeo A (Azevedo et al., 2017), pães isentos de glúten e de sacarose (Morais et al., 2013), sobremesa láctea de chocolate adoçado com adoçantes de alta potência (Morais et al., 2014) e sorvetes comerciais sabor baunilha (Cadena \& Bolini, 2011).

O objetivo do presente estudo foi desenvolver e estudar sensorialmente sorvete sabor chocolate simbiótico com substituição do açúcar por agentes adoçantes (também chamados edulcorantes), com o propósito de obter um produto menos calórico, com teor reduzido de açúcar, simbiótico e com boa aceitação pelos consumidores.

\section{Materiais e métodos}

\subsection{Materiais}

Foram desenvolvidas oito amostras de sorvete de chocolate com Lactobacillus acidophilus microencapsulados: a amostra padrão (ou tradicional) adoçada com sacarose (não contendo inulina em sua formulação) e outras sete amostras com substitutos de sacarose, contendo inulina em sua formulação. Os edulcorantes utilizados foram: Aspartame (Sweetmix, Sorocaba, Brasil), Sucralose, SPLENDA (Tovani Benzaquen, São Paulo, Brazil), Neotame (Tovani Benzaquen, São Paulo, Brazil) e Estévia com 60\%, 80\%, 95\%, 97\% de Rebaudiosídeo A (Steviafarma, Maringá, Brazil). Foi utilizada inulina Orafti® HSI (Beneo Latinoamericana Ltda., São Paulo, Brazil) e Lactobacillus acidophilus, La-5, CHR Hansen® (São Paulo, Brasil).

Os ingredientes utilizados nos sorvetes foram: leite em pó Itambé ${ }^{\circledR}$ (São Paulo, Brazil), água, sacarose União (Araras, Brazil), creme de leite Itambé® (São Paulo, Brazil), Estabilizante Starmixpremium Kerry (São Paulo, Brazil), Glucose Nutre (São Paulo, Brazil), Cacau em pó Harald. 


\subsection{Métodos}

\subsubsection{Processamento dos sorvetes de chocolate.}

As formulações das amostras estão descritas na Tabela 1. As concentrações dos ingredientes foram estabelecidas em estudo prévio, no qual foi aplicada análise tempo-intensidade para determinação das concentrações dos edulcorantes em mesma doçura equivalente à sacarose $14,5 \%$ em sorvete de chocolate (Peres, 2018). A cultura de L. acidophilus microencapsulados e liofilizados $\left(0,03 \% \mathrm{w} / \mathrm{v}, 10^{10} \log \mathrm{CFU} / \mathrm{g}\right)$ foi adicionada à calda do sorvete previamente pasteurizada.

Tabela 1. Composição usada nas formulações dos sorvetes tradicional e de baixo valor energético.

\begin{tabular}{ccccccccc}
\hline \multirow{2}{*}{$\begin{array}{c}\text { Ingredientes } \\
(\%)\end{array}$} & IC1 & IC2 & IC3 & IC4 & IC5 & IC6 & IC7 & IC8 \\
\cline { 2 - 9 }$y$ & 14,5000 & 15,5000 & 15,5000 & 15,500 & 15,5000 & 15,5000 & 15,5000 & 15,5000 \\
\hline Leite em pó & 61,0000 & 62,3000 & 62,3000 & 62,3000 & 62,3000 & 62,3000 & 62,3000 & 62,3000 \\
\hline Água & 9,4000 & 0,0410 & 0,0120 & 0,0017 & 0,0750 & 0,0750 & 0,0750 & 0,0750 \\
\hline Adoçante & 5,0000 & 5,0000 & 5,0000 & 5,0000 & 5,0000 & 5,0000 & 5,0000 & 5,0000 \\
\hline Gordura & 0,4000 & 0,4000 & 0,4000 & 0,4000 & 0,4000 & 0,4000 & 0,4000 & 0,4000 \\
\hline Estabilizante & 3,0000 & 3,0000 & 3,0000 & 3,0000 & 3,0000 & 3,0000 & 3,0000 & 3,0000 \\
\hline Glucose & 7,0000 & 7,0000 & 7,0000 & 7,000 & 7,0000 & 7,0000 & 7,0000 & 7,0000 \\
\hline Cacau em pó & - & 6,7000 & 6,7000 & 6,7000 & 6,7000 & 6,7000 & 6,7000 & 6,7000 \\
\hline Inulina & - & &
\end{tabular}

Agentes adoçantes em cada formulação de sorvete: Sacarose: IC1. Sucralose: IC2. Aspartame: IC3. Neotame: IC4. Estévia 60: IC5. Estévia 80: IC6. Estévia 95: IC7. Estévia 97: IC8.

\subsubsection{Análise sensorial}

Através da aplicação da análise tempo-intensidade (TI) e do teste de aceitação, as amostras foram analisadas sensorialmente. Os perfis temporais de sabor de leite e gostos doce e amargo foram determinados, bem como a aceitação dos produtos obtidos.

A) Análise tempo-intensidade

As análises foram conduzidas em cabines individuais em temperatura de $20{ }^{\circ} \mathrm{C}$ e os provadores recebiam água para que a limpeza do palato fosse realizada.

Os testes foram realizados no Laboratório de Ciências Sensoriais e Estudo do Consumidor na Faculdade de Engenharia de Alimentos (Universidade Estadual de Campinas). As amostras foram apresentadas em copos plásticos descartáveis de $30 \mathrm{~mL}$ codificados com três dígitos de números previamente balanceados, em bandeja de isopor.

A pré-seleção dos provadores ocorreu através de testes triangulares aplicados à análise sequencial de Wald (Amerine et al., 1965; Meilgaard et al., 2007). Nos testes triangulares, foram utilizadas duas amostras de leite achocolatado com diferença de doçura significativamente perceptível entre elas em nível de 1\% de significância (Cadena \& Bolini, 2011; Cardoso \& Bolini, 2007; Cavallini \& Bolini, 2005).

Dos 30 candidatos iniciais, 20 foram pré-selecionados para realizarem as etapas seguintes.

B) Treinamento dos provadores

A análise tempo-intensidade (TI) foi aplicada em relação aos termos descritores que poderiam ser alterados em função da substituição de sacarose no sorvete: gosto doce, gosto amargo e sabor de leite, os quais foram analisados separadamente. 
O treinamento dos candidatos a provadores foi realizado com o propósito de formar a memória sensorial pelo contato direto com as referências da escala de intensidade utilizada. Os candidatos provaram as referências correspondentes às intensidades zero (nenhuma) e nove (máxima) na escala utilizada (Tabela 2) em relação aos três estímulos escolhidos pelo grupo, por serem importantes no produto: doçura, amargor e sabor de leite. Foram realizadas seis sessões de treinamento (Cadena \& Bolini, 2011; Cardoso \& Bolini, 2007; Cavallini \& Bolini, 2005).

Tabela 2. Descritores, definições e referências utilizadas pelos provadores.

\begin{tabular}{|c|c|c|}
\hline Descritores & Definições & Referências \\
\hline Leite & $\begin{array}{l}\text { Sabor característico de leite integral } \\
\text { UHT comercial marca Nestlé Ninho® } \\
\text { com } 7 \text { dias de vida de prateleira }\end{array}$ & $\begin{array}{c}\text { Nenhum (intensidade 0): } \\
\text { água desionizada a } 22^{\circ} \mathrm{C} \\
\text { Muito (intensidade 9): } \\
17 \text { gramas de leite em pó Ninho Nestlé@ Integral } \\
\text { Solúvel dissolvidos em } 83 \mathrm{~mL} \text { de água purificada } \\
\text { (em purificador Eletrolux) } \\
\text { a } 22^{\circ} \mathrm{C}\end{array}$ \\
\hline Amargo & $\begin{array}{l}\text { Gosto amargo característico de cafeína } \\
\text { diluída em água }\end{array}$ & $\begin{array}{l}\text { Nenhum (intensidade 0): } \\
\text { água desionizada a } 22^{\circ} \mathrm{C} \\
\text { Muito (intensidade 9): } \\
\text { Solução aquosa a } 0,1 \% \text { de estévia } \\
\text { com } 60 \% \text { de rebaudiosídeo A }\end{array}$ \\
\hline Doce & $\begin{array}{c}\text { Gosto doce característico de sacarose } \\
\text { diluída em água }\end{array}$ & $\begin{array}{l}\text { Nenhum (intensidade 0): } \\
\text { água desionizada a } 22{ }^{\circ} \mathrm{C} \\
\text { Muito (intensidade 9): } \\
\text { Solução aquosa a } 0,05 \% \text { de } \\
\text { aspartame em água. }\end{array}$ \\
\hline
\end{tabular}

C) Seleção da equipe definitiva para realização da análise tempo-intensidade

Nesta etapa, vinte candidatos provaram as amostras em blocos completos balanceados em quatro repetições em apresentação monádica sequencial (Wakeling \& MacFie, 1995), com intervalo mínimo de duas horas entre cada teste (Cadena \& Bolini, 2011).

Os testes foram realizados utilizando uma escala linear mista de zero a nove, na qual $0=$ nenhuma intensidade; 4,5 = intensidade moderada e 9 = intensidade máxima (Palazzo \& Bolini, 2009), a qual era mostrada na tela do computador.

Ao ouvir o primeiro sinal sonoro emitido pelo programa de coleta de dados TI (tempo previamente aprovado e padronizado em função do tipo do produto em teste), o provador deveria colocar na boca toda a amostra apresentada $(20 \mathrm{~mL})$ e indicar a intensidade do descritor sensorial em análise na escala de intensidade. Ao segundo sinal sonoro, o provador deveria deglutir a amostra. Ao terceiro sinal, era indicada a finalização do teste.

Os provadores utilizavam o deslizamento do "mouse" sobre a escala para registrar a intensidade do descritor analisado.

Para realização da coleta de dados da análise de tempo-intensidade, foi utilizado o software Time Intensity Analysis of Food and Tastes - TIAF, desenvolvido e registrado na Universidade Estadual de Campinas - UNICAMP (Bolini, 2012). Após a coleta de dados dos provadores, os parâmetros das curvas tempo-intensidade registrados pelo software e analisados estatisticamente foram: Imax (Intensidade máxima percebida pelo provador), TImax (Tempo em que a intensidade máxima foi percebida), Área (área sob a curva registrada) e Ttot (tempo total de percepção do descritor) (Palazzo \& Bolini, 2009). 
Quatorze, de vinte provadores, foram selecionados por apresentarem resultados que demonstraram a capacidade de discriminação (valores de pFamostra <0,30) e repetibilidade (valores de pFrepetição >0,05), além de consenso individual nas repetições e entre os membros do grupo (Damásio \& Costell, 1991).

D) Análise tempo-intensidade-múltipla

Nesta etapa, foi também utilizado o software Time Intensity Analysis of Food and Tastes - TIAF, sendo, a escala utilizada, as condições e instruções na coleta de dados, bem como a quantidade de cada uma das amostras analisadas, as mesmas mencionadas no item C) Seleção da equipe definitiva para realização da análise tempo-intensidade.

Assim, os 14 provadores selecionados realizaram a análise tempo-intensidade do gosto doce, do gosto amargo e do sabor de leite separadamente, sendo cada uma delas novamente em delineamento experimental de blocos completos balanceados em quatro repetições de forma monádica sequencial (Wakeling \& MacFie, 1995), com intervalo mínimo de duas horas entre cada teste (Cadena \& Bolini, 2011).

A análise tempo-intensidade tradicional permite a comparação de diferentes amostras em relação a uma única característica sensorial em função do tempo, enquanto a análise tempo-intensidade múltipla permite a representação e a comparação de diferentes descritores analisados em cada uma das amostras separadamente, permitindo a interpretação do conjunto das características sensoriais na sequência e no tempo em que são percebidas durante o consumo do produto em estudo.

A análise tempo-intensidade múltipla foi realizada por haver coleta de dados rigorosamente padronizada, na qual o tempo para levar o alimento à boca, o tempo para engolir o alimento e o tempo de registro da intensidade percebida pelo provador como resposta sensorial foram realizados de forma sistemática em tempo e condições pré-definidas e controladas por meio do software utilizado. A quantidade de cada uma das amostras apresentadas aos provadores foi padronizada em 20 gramas.

As curvas foram calculadas e plotadas usando as médias dos parâmetros coletados e em razão dos critérios dos valores de pFamostra e pFrepetição aplicados na seleção dos provadores, separadamente para cada estímulo (American Society for Testing and Materials, 2017).

E) Análise de aceitação

Cento e vinte provadores consumidores de sorvete de chocolate participaram da análise de aceitação por divulgação eletrônica. Os consumidores tinham entre 17 e 45 anos sendo $50 \%$ homens e 50\% mulheres.

O teste foi conduzido no Laboratório de Ciência Sensorial e Estudos de Consumidor da UNICAMP. Vinte gramas de cada uma das amostras de sorvete de chocolate eram oferecidos na temperatura de $-2{ }^{\circ} \mathrm{C} \mathrm{em}$ copos plásticos codificados com três dígitos.

A análise de aceitação foi realizada utilizando escala hedônica linear de nove centímetros, ancorada, na esquerda, pelas palavras "desgostei extremamente", e à direita, "gostei extremamente" (Stone \& Sidel, 2003). Os consumidores avaliaram o quanto gostaram das amostras em relação a aparência, aroma, sabor, textura e impressão global. Todas as amostras foram apresentadas em blocos completos balanceados e de forma monádica sequencial (Wakeling \& MacFie, 1995; Guinard et al., 1997).

\subsubsection{Determinações físico-químicas}

\subsubsection{Overrun}

Em béqueres de $100 \mathrm{~mL}$, foram pesadas as caldas e, posteriormente, os sorvetes, depois do congelamento. O overrun foi determinado a partir do cálculo da Equação 1 de Marshall et al. (2003) e as análises foram feitas em triplicata.

$\%$ Overrun $=\frac{(\text { peso da calda }- \text { peso do sorvete }) \times 100}{\text { peso do sorvete }}$ 


\subsubsection{Velocidade do derretimento}

A medida da velocidade de derretimento foi realizada de acordo com o procedimento descrito por Marshall et al. (2003). As análises foram realizadas em triplicatas para as oito amostras de sorvete previamente pesadas, contendo aproximadamente $250 \mathrm{~g}$. As amostras foram acondicionadas em oito peneiras com MESH 14, apoiadas em suportes para bureta com anel cíclico contendo um funil. Abaixo do funil, havia uma proveta de $250 \mathrm{~mL}$ para coleta do sorvete derretido e avaliação da quantidade obtida através do tempo.

\subsubsection{Determinação de $\mathrm{pH}$}

$\mathrm{O}$ pH foi medido em potenciômetro, de acordo com metodologia proposta por Park \& Antonio (2006), utilizando $100 \mathrm{~mL}$ de cada amostra homogeneizada, sendo as análises realizadas em triplicata.

\subsubsection{Análise estatística}

Os resultados obtidos nas análises físico-químicas, análise de parâmetros das curvas TI e análise de aceitação foram submetidos à análise de variância (ANOVA) e as médias foram comparadas pelo teste de Tukey $(p<0,05)$.

Os parâmetros das curvas tempo-intensidade foram submetidos também à análise de componentes principais e os dados de aceitação à análise multivariada, para gerar o mapa interno de preferência.

As análises estatísticas foram analisadas utilizando o Software Statistical Analysis System - SAS 9.4 (Statistical Analysis System, 2012).

\section{Resultados e discussão}

\subsection{Análise tempo-intensidade: estímulo amargor}

As amostras não apresentaram diferença significativa $(p>0,05)$ em relação ao tempo em que foi percebida a intensidade máxima de amargor (TImax). Já em relação à intensidade máxima (Imax), as amostras adoçadas com sacarose e sucralose não diferiram significativamente entre si $(p>0,05)$ e aquelas adoçadas com neotame e estévia contendo as diferentes concentrações de rebaudiosídeo $\mathrm{A}$, como também não diferiram significativamente entre si $(p>0,05)$. Já a amostra de sorvete adoçado com aspartame apresentou Imax intermediária, diferindo significativamente de todas as demais amostras $(p<0,05)$.

O tempo total de percepção dos estímulos variou amplamente entre os sorvetes, em que as amostras adoçadas com estévia e neotame apresentaram tempos de percepção mais prolongados, o que evidenciou a presença de gosto residual amargo com maior tempo de duração que as demais amostras, em acordo com resultados publicados por Nofre \& Tintil (2000).

No estudo realizado por Palazzo \& Bolini (2013) com chocolate ao leite, também foram encontrados maiores valores de tempo total de percepção nas amostras adoçadas com neotame e estévia, comprovando a relação de maior residual amargo em produtos formulados com estévia.

\subsection{Análise tempo-intensidade: estímulo doce}

Em relação ao tempo em que o estímulo máximo de doçura foi percebido (TImax), as amostras não diferiram significativamente entre si $(p>0,05)$.

Em relação ao parâmetro Imax (Intensidade máxima percebida), verifica-se que as amostras formuladas com sacarose, sucralose e com estévia em todas as concentrações rebaudiosídeo A estudadas não apresentaram diferença entre elas, e que a amostra formulada com aspartame difere significativamente de todas as outras $(p>0,05)$. 
Analisando o tempo máximo de percepção do estímulo doce, verificou-se que as amostras adoçadas com estévia apresentaram as maiores médias de tempos para a percepção do estímulo doce, ou seja, apresentando um residual doce prolongado. Ferraz (2013) encontraram valores semelhantes para tempo de percepção de residual doce nos sorvetes de creme adoçados com estévia, neotame e sucralose.

Palazzo \& Bolini (2013), em estudo feito em chocolate ao leite, também encontraram valores superiores de percepção de residual doce nas amostras adoçadas com estévia e neotame. Já os autores Cadena \& Bolini (2011) encontraram valor semelhante de residual doce em sorvete de creme adoçado com sucralose.

\subsection{Análise tempo-intensidade: estímulo sabor de leite}

Em TImax, tempo em que a intensidade máxima de sabor de leite é percebida, as amostras não apresentaram diferença significativa entre elas $(p>0,05)$. Em relação ao parâmetro Imax, as amostras adoçadas com sacarose e sucralose não apresentaram diferença estatística entre elas, e as amostras adoçadas com estévia $80 \%$ e $95 \%$ de rebaudiosídeo adoçadas com estévia também não diferem entre si $(p>0,05)$.

A amostra com sacarose apresentou o tempo total de percepção do descritor superior, não diferindo daquelas adoçadas com sucralose, neotame e estévia com $95 \%$ de rebaudiosídeo A $(p>0,05)$.

\subsection{Análise tempo-intensidade múltipla}

Na Figura 1, encontram-se representados os perfis dinâmicos, ou seja, a representação da análise tempo-intensidade múltipla de cada amostra de sorvete de chocolate. São representadas as curvas dos três descritores analisados (doce, amargo e sabor de leite), para cada uma das amostras analisadas.

A análise de TI-múltiplo é a forma utilizada para interpretação dos dados obtidos a partir das médias dos parâmetros, comparando dois ou mais estímulos que foram analisados sob as mesmas condições de padronização (Palazzo \& Bolini, 2013; American Society for Testing and Materials, 2017).

As amostras adoçadas com sacarose e sucralose apresentaram curvas com perfis semelhantes, sem do que ambas as amostras possuem um sabor de leite e uma doçura acentuadas e um residual amargo pequeno.

As amostras adoçadas com estévia com diferentes concentrações de rebaudiosídeo apresentaram um perfil com as mesmas tendências, evidenciando que as diferentes concentrações de rebaudiosídeo A presentes não influenciaram no perfil das curvas das amostras nos três estímulos, doçura, amargor e sabor de leite, ou seja, a estévia, como adoçante, mesmo em maiores concentrações de rebaudiosídeo A (95\% e 97\%), os gostos doce e amargo mantiveram-se acentuados nas amostras. Esses resultados encontram-se em concordância com aqueles encontrados por Giri et al. (2012) em estudos com produtos adoçados com estévia.

O sorvete adoçado com aspartame foi caracterizado pelo amargor e pequenas curvas para doçura e sabor de leite. A amostra adoçada com neotame apresentou um residual amargo acentuado, semelhante ao das amostras adoçadas com estévia. 
a) Sacarose

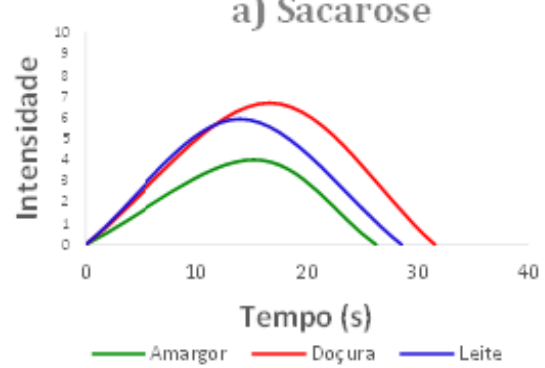

c) Sucralose

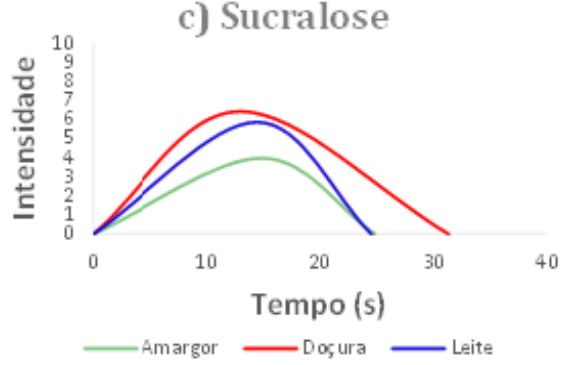

e) Estévia $60 \%$ rebaudiosídeo A

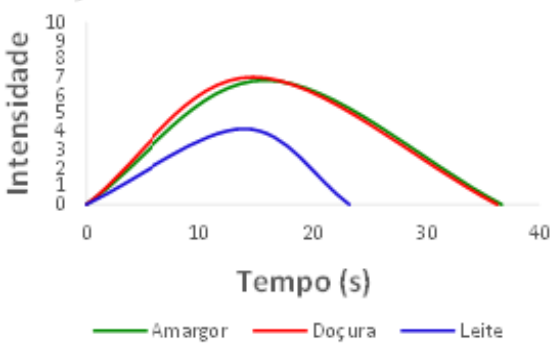

g) Estévia 95\% rebaudiosídeo A

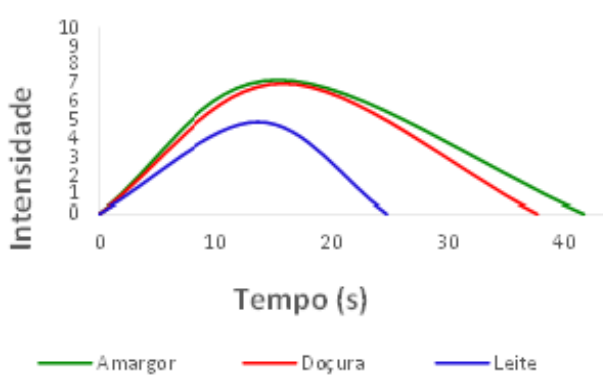

b) Aspartame

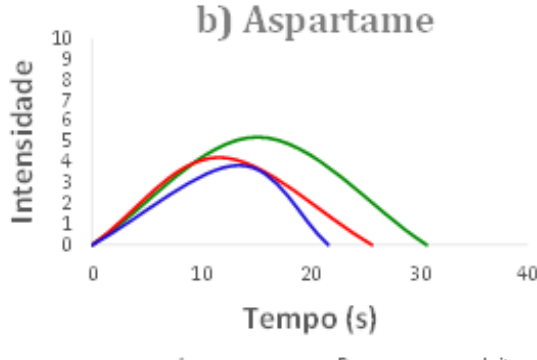

- Amargor _- Dosura - leite

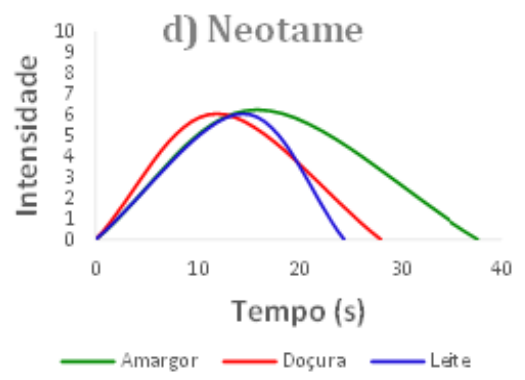

f) Estévia 85\% rebaudiosídeo A

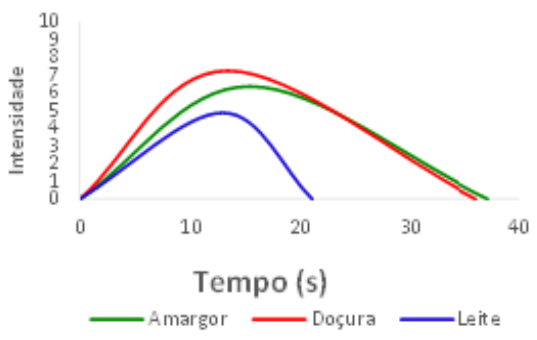

h) Estévia 97\% rebaudiosídeo A

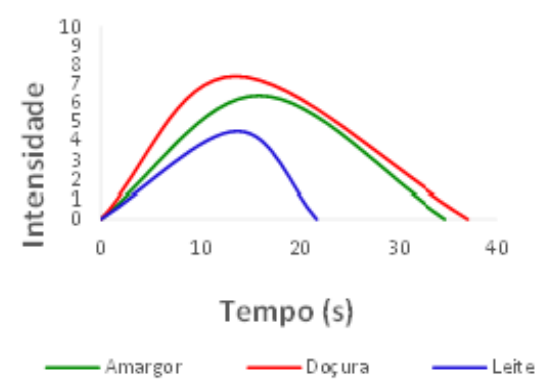

Figura 1. Representação de perfil tempo-intensidade múltipla de doçura, sabor leite e amargor dos sorvetes adoçados com (a) sacarose; (b) aspartame; (c) sucralose; (d) neotame; (e) estévia $60 \%$ rebaudiosídeo A; (f) estévia $80 \%$ rebaudiosídeo A; (g) estévia 95\% rebaudiosídeo A; e (h) estévia 97\% rebaudiosídeo A.

O resultado da análise de componentes principais das curvas tempo-intensidade múltipla encontra-se representado na Figura 2. Nesta análise multivariada, cada produto se localiza próximo ao vetor que o caracteriza. A amostra com sacarose e sucralose foram caracterizadas principalmente pelo sabor de leite. Essa informação evidencia que a amostra adoçada com sucralose apresenta perfil sensorial da percepção dinâmica mais próximo ao perfil da amostra adoçada com sacarose. 
Já as amostras estévia com $60 \%, 80 \%, 95 \%$ e $97 \%$ de rebaudiosídeo A foram caracterizadas pelo amargor, independentemente da concentração do rebaudiosídeo A, diferentemente das afirmações dos trabalhos publicados por Goto \& Clemente (1998), que trabalharam com a estévia solubilizada em água.

Esses resultados evidenciam a importância de pesquisas com edulcorantes em alimentos, uma vez que o poder adoçante e as características de intensidade, tempo de duração, início e extinção de sabores podem variar em função do meio de dispersão, temperatura e concentração em que se apresentam.

A formulação adoçada com sucralose possibilitou a obtenção do sorvete de chocolate de baixa caloria simbiótico sem diferença significativa com o produto adoçado com sacarose, em percepção simultânea de doçura, amargor e sabor de leite $(p>0,05)$. Os sorvetes adoçados com aspartame, neotame e estévia apresentaram gosto amargo mais intenso e com maior tempo de duração $(p<0,05)$.

A aplicação da análise tempo-intensidade múltipla possibilitou interpretar o conjunto de importantes características sensoriais (gostos doce e amargo, sabor chocolate e sabor leite) das amostras de sorvetes de chocolate simbiótico de baixa caloria com diferentes edulcorantes na sequência e no tempo em que são percebidas durante o consumo do produto em estudo, as quais não poderiam ser observadas por análise tempo-intensidade tradicional.

\subsection{Análise de aceitação}

Todas as amostras de sorvete de chocolate obtiveram médias de aceitação superiores a 4,8 (Tabela 3), em relação a aparência, aroma, sabor, textura e impressão global. Esse resultado pode ser interpretado como positivo, uma vez que o ponto central de indiferença (não gostei e nem desgostei) da escala corresponde ao valor 4,5 (Lawless \& Heymann, 2010) e, portanto, as médias acima de 4,8 indicam uma tendência a "gostar" do produto.

Analisando a aceitação em relação à aparência, a amostra adoçada com sucralose e estévia com $80 \%$ de rebaudiosídeo A apresentam diferença estatística entre elas $(p<0,05)$. Na aceitação em relação ao aroma, as amostras não diferem significativamente entre si, uma vez que, com baixas temperaturas, a volatilização de aromas diminui (Chmiel et al., 2017).

Em relação ao sabor, as amostras com sacarose, aspartame e estévia com $80 \%$ de rebaudiosídeo A diferem significativamente $(p<0,05)$, e as amostras com sucralose, estévia com $60 \%$ e $95 \%$ de rebaudiosídeo A, não diferem entre si $(p>0,05)$. A amostra adoçada com sacarose (sem inulina em sua formulação) apresentou média significativamente superior às demais amostras $(p<0,05)$.

Estudo feito por Cadena \& Bolini (2011), em sorvete de creme comerciais tradicionais e light, as amostras adoçadas com sacarose também apresentaram notas superiores.

Em relação à textura dos sorvetes de chocolate, as amostras com sucralose e estévia com $95 \%$ e $97 \%$ de rebaudiosídeo A não diferem entre si $(p>0,05)$. A amostra estévia com $80 \%$ de rebaudiosídeo A obteve média inferior entre as amostras de sorvete $(p<0,05)$. 


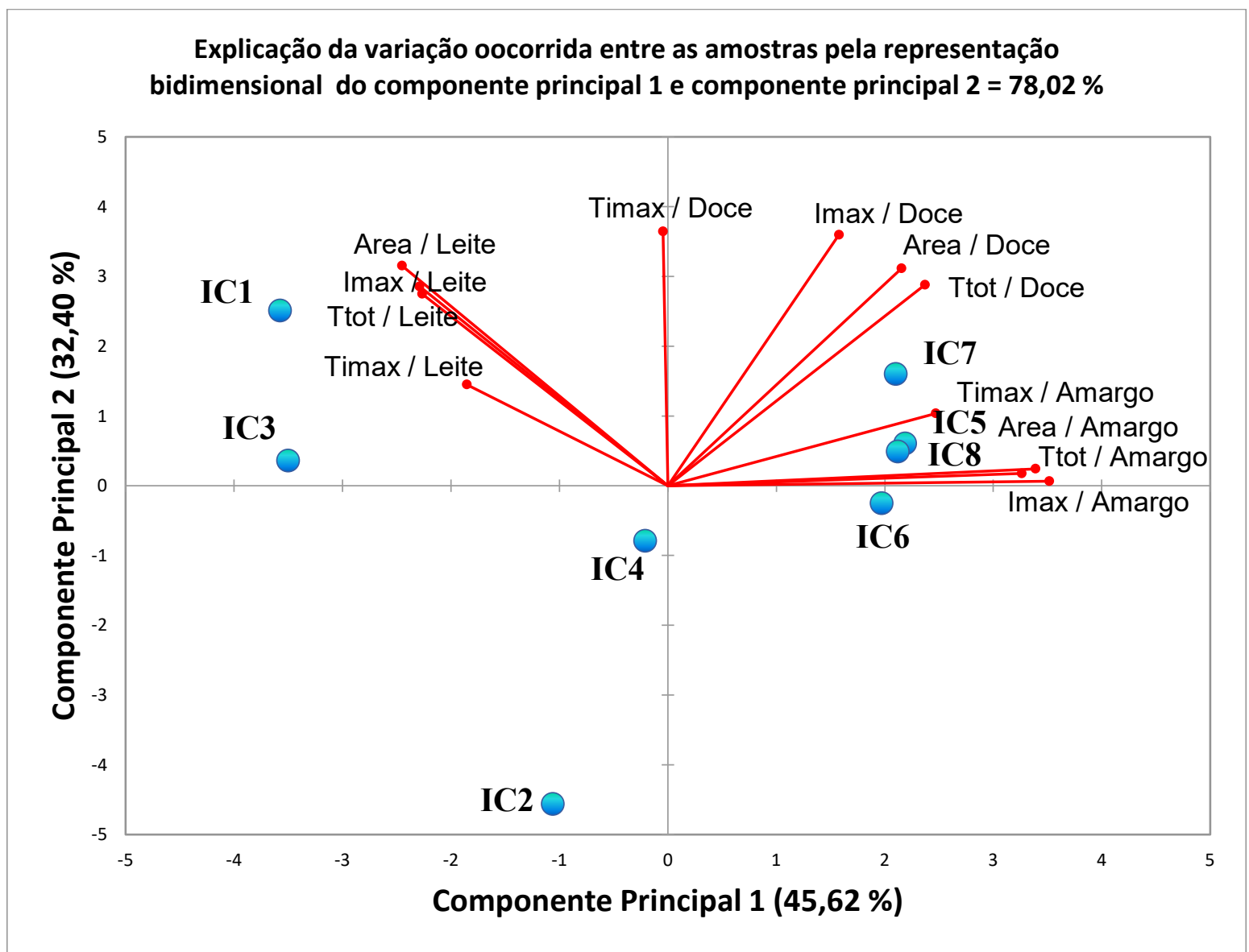

Figura 2. Análise de componentes principais dos parâmetros das curvas tempo-intensidade múltipla (doce, amargo e leite) das amostras de sorvetes de chocolate preparados com diferentes adoçantes. Sacarose: IC1. Aspartame: IC2. Sucralose: IC3. Neotame: IC4. Estévia 60\% rebaudiosídeo IC5. E1stévia 80\% rebaudiosídeo: IC6. Estévia 95\% rebaudiosídeo: IC7. Estévia 97\% rebaudiosídeo: IC8. Timax: tempo da intensidade máxima. Imax: intensidade máxima. Area: área sob a curva. Ttot: tempo total do estímulo.

Os sorvetes apresentaram médias maiores que 5,0 em relação à impressão global, sendo que as amostras com sacarose, sucralose e estévia com 95\% e 97\% de rebaudiosídeo não diferiram entre si $(p>0,05)$.

Observando a relação da aceitação em relação ao sabor e à impressão global, é possível verificar a mesma tendência de aceitação, uma vez que as amostras que apresentaram maior preferência em relação ao sabor (Figura 3c) foram preferidas também em impressão global (Figura 3e). Desta forma, fica evidenciada a influência que o sabor exerce na aceitação dos sorvetes.

É possível constatar essa informação nos resultados da distribuição e do posicionamento das amostras (representadas pelos círculos azuis) em relação à distribuição dos consumidores (em pontos vermelhos, que ficam localizados próximos às amostras de maior preferência e distantes das amostras menos preferidas).

Estudos feitos por Drake \& Gerard (2003), Drake et al. (1999) e por Melo et al. (2009) também encontraram resultados concordantes, nos quais ficou evidenciado que o sabor influencia diretamente a aceitação global das amostras.

$\mathrm{Na}$ aceitação em relação à aparência (Figura 2a), aroma (Figura 2b) e textura (Figura 2d), nota-se que o posicionamento dos consumidores em relação às amostras não segue a mesma tendência de proximidade que no gráfico relativo à impressão global, sugerindo que a interferência da aparência na aceitação global do produto provavelmente será menos marcante do que o sabor. 
É provável que as amostras IC1 e IC3 apresentaram preferência alta e sem diferença pelos consumidores por apresentarem o perfil tempo-intensidade múltiplo com parâmetros dos três descritores sem diferença significativa $(p>0,05)$.

As amostras IC2, IC4, IC5, IC6, IC7 e IC8 apresentaram menor preferência por apresentarem perfil de amargor com parâmetros significativamente superiores e perfis de sabor de leite significativamente inferiores $(p<0,05)$.

a) Aparência

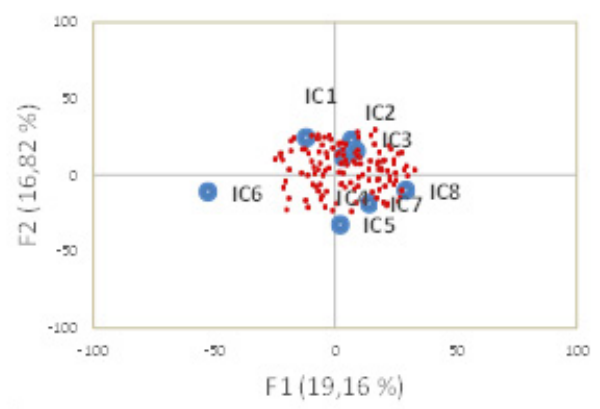

c) Sabor

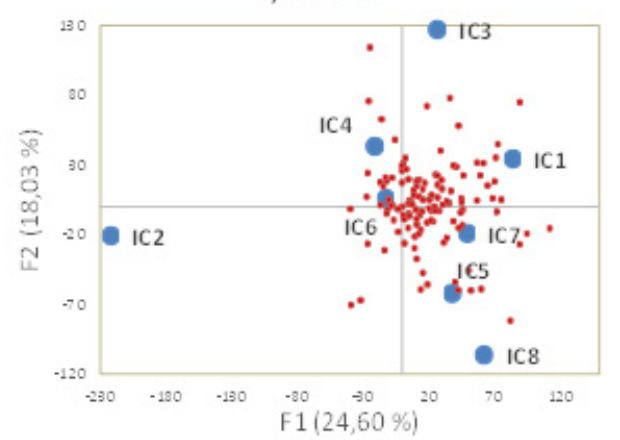

b) Aroma

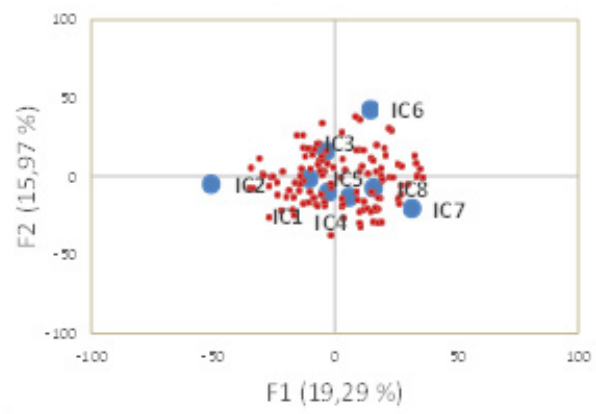

d) Textura

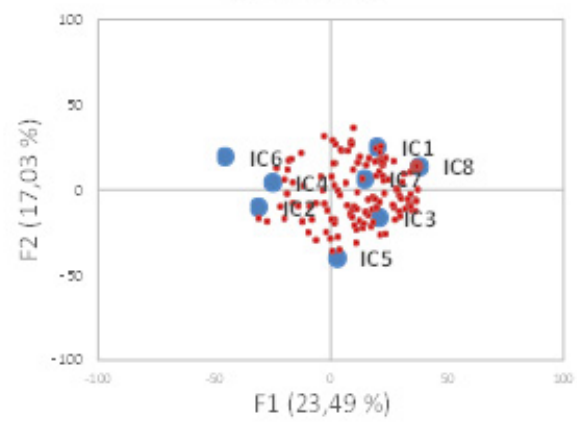

e) Impressão global

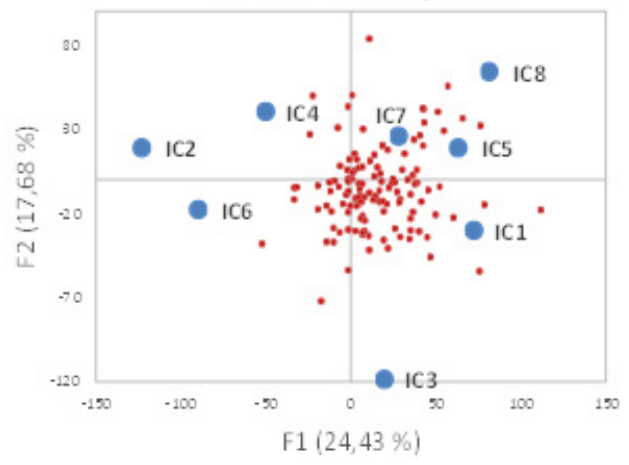

Figura 3. Mapa de preferência interno das amostras de sorvete em relação a: (a) aparência; (b) aroma; (c) sabor; (d) textura; (e) impressão global. Amostras de sorvete de chocolate preparado com diferentes adoçantes: Sacarose; IC1. Aspartame: IC2. Sucralose: IC3. Neotame: IC4. Estévia 60\% rebaudiosídeo: IC5. Estévia 80\% rebaudiosídeo: IC6. Estévia 95\% rebaudiosídeo: IC7. Estévia 97\% rebaudiosídeo: IC8. 


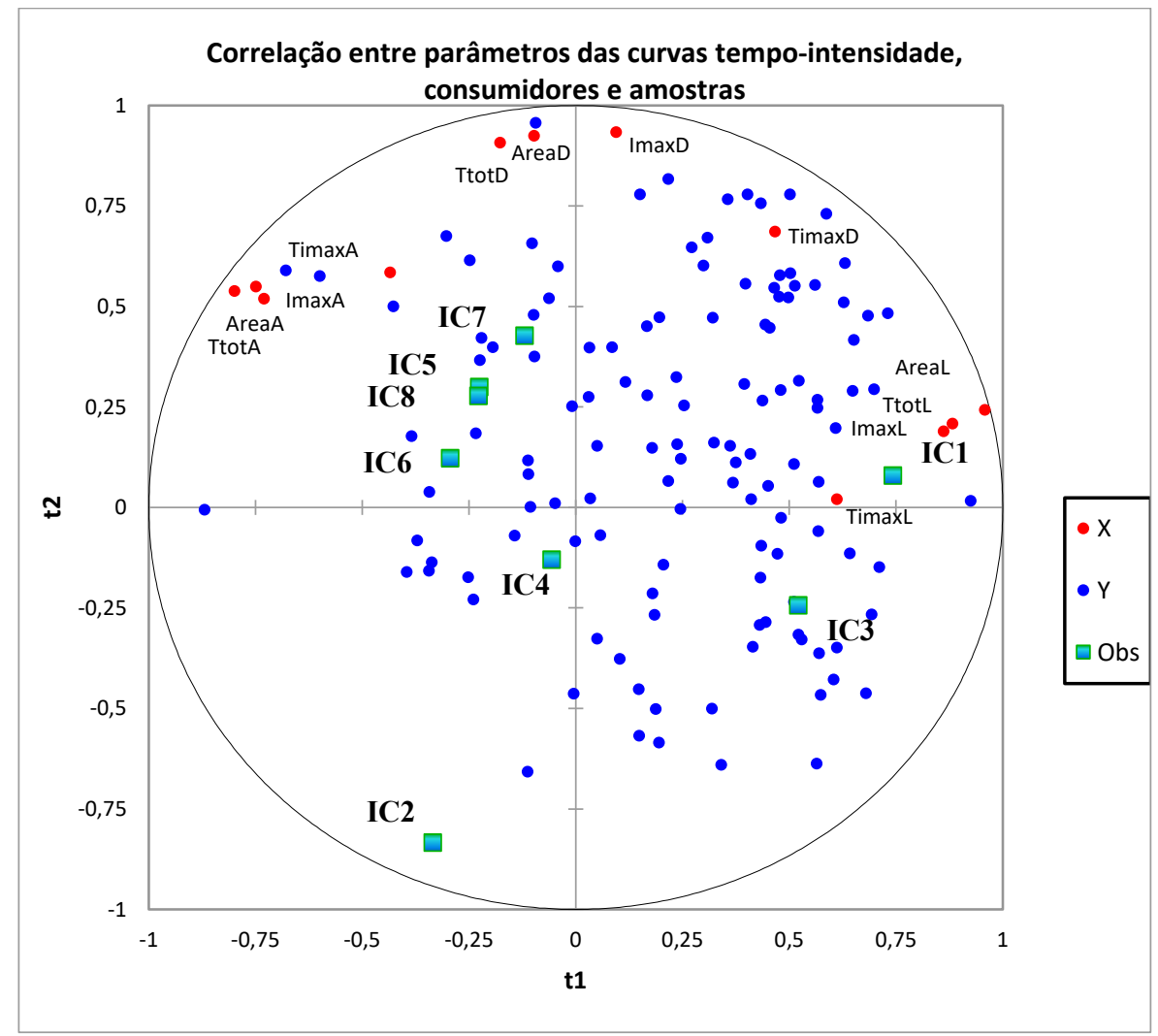

Figura 4. Mapa externo de preferência gerado pela análise de regressão por quadrados mínimos parciais entre dados de aceitação global e parâmetros das curvas de gosto amargo, doce e sabor de leite. Amostras de sorvete de chocolate preparado com diferentes adoçantes: Sacarose: IC1. Aspartame: IC2. Sucralose: IC3. Neotame: IC4. Estévia 60\% rebaudiosídeo IC5. Estévia 80\% rebaudiosídeo: IC6. Estévia 95\% rebaudiosídeo: IC7. Estévia 97\% rebaudiosídeo: IC8. Timax: tempo da intensidade máxima. Imax: intensidade máxima. Area: area sob a curva. Ttot: tempo total do estímulo. $\mathrm{x}$ (pontos azuis): parâmetros das curvas tempo-intensidade. $\mathrm{y}$ (pontos vermelhos): consumidores. $t 1$ : valor padronizado na correlação entre amostras e consumidores.t2: valor padronizado na correlação entre amostras e parâmetros das curvas tempo-intensidade.

Tabela 3. Médias* de aceitação das amostras de sorvete de chocolate com diferentes edulcorantes.

\begin{tabular}{ccccccccc}
\hline Aceitação & IC1 & IC2 & IC3 & IC4 & IC5 & IC6 & IC7 & IC8 \\
\hline Aparência & $6,0^{\mathrm{ab}}$ & $6,0^{\mathrm{ab}}$ & $6,3^{\mathrm{a}}$ & $6,0^{\mathrm{ab}}$ & $5,8^{\mathrm{ab}}$ & $5,2^{\mathrm{b}}$ & $5,7^{\mathrm{ab}}$ & $6,2^{\mathrm{ab}}$ \\
\hline Aroma & $5,7^{\mathrm{a}}$ & $5,6^{\mathrm{a}}$ & $5,8^{\mathrm{a}}$ & $5,6^{\mathrm{a}}$ & $5,6^{\mathrm{a}}$ & $5,4^{\mathrm{a}}$ & $5,6^{\mathrm{a}}$ & $5,9^{\mathrm{a}}$ \\
\hline Sabor & $6,7^{\mathrm{a}}$ & $5,0^{\mathrm{d}}$ & $6,3^{\mathrm{abc}}$ & $5,9^{\mathrm{bc}}$ & $6,2^{\mathrm{abc}}$ & $5,7^{\mathrm{c}}$ & $6,5^{\mathrm{ab}}$ & $6,2^{\mathrm{abc}}$ \\
\hline Textura & $6,0^{\mathrm{ab}}$ & $5,5^{\mathrm{bcd}}$ & $6,4^{\mathrm{a}}$ & $5,2^{\mathrm{dc}}$ & $5,8^{\mathrm{abc}}$ & $4,8^{\mathrm{d}}$ & $6,2^{\mathrm{a}}$ & $6,2^{\mathrm{a}}$ \\
\hline Impressão Global & $6,5^{\mathrm{a}}$ & $5,3^{\mathrm{c}}$ & $6,3^{\mathrm{a}}$ & $5,5^{\mathrm{bc}}$ & $5,9^{\mathrm{ab}}$ & $5,3^{\mathrm{bc}}$ & $6,2^{\mathrm{a}}$ & $6,2^{\mathrm{a}}$ \\
\hline
\end{tabular}

*Médias marcadas com letras iguais na mesma linha não diferem significativamente entre si, de acordo com o teste de Tukey $(p>0,05)$. IC1: Sacarose. IC2: Aspartame. IC3: Sucralose. IC4: Neotame. IC5: Estévia 60. IC6: Estévia 80. IC7: Estévia 95. IC8: Estévia 97.

A partir dos resultados obtidos no teste de consumidor e na análise de TI, foi realizada análise de componentes principais (ACP), a fim de se identificar quais parâmetros dos estímulos doce, amargo e sabor de leite através do TI influenciam na formação do sabor das amostras (Figura 4).

É possível verificar na Figura 4 que a área sob a curva, o tempo total de duração e a intensidade máxima do sabor de leite influenciara positivamente na aceitação de sorvetes de chocolate, o que é uma importante explicação para a preferência das amostras adoçadas com sacarose e com sucralose. 


\subsection{Caracterização físico-química}

\subsubsection{Overrun}

Segundo a resolução n. ${ }^{\circ} 266$ da ANVISA (Brasil, 2005), a quantidade mínima de overrun exigida na legislação é de $45 \%$ de ar na composição dos sorvetes, pois assim a leveza característica presente nos sorvetes é preservada. O overrun influencia na dureza e na estrutura dos sorvetes, pois o ar presente no overrun garante aos sorvetes uma leveza e cremosidade, além de influenciar no derretimento dos sorvetes (Ferraz et al., 2012).

A Tabela 4 expõe os valores encontrados para os níveis de overrun dos sorvetes, em que é possível verificar que as amostras estão de acordo com a legislação e não apresentam diferença significativa entre si $(p>0,05)$.

Tabela 4. Médias* de Overrun e pH das amostras de sorvetes.

\begin{tabular}{ccc}
\hline Amostras & Overrun (\%) & pH \\
\hline Sacarose (IC1) & $50^{\mathrm{a}}$ & $6,2^{\mathrm{a}}$ \\
\hline Aspartame (IC2) & $47^{\mathrm{a}}$ & $6,1^{\mathrm{a}}$ \\
\hline Sucralose (IC3) & $48^{\mathrm{a}}$ & $6,0^{\mathrm{a}}$ \\
\hline Neotame (IC4) & $47^{\mathrm{a}}$ & $6,2^{\mathrm{a}}$ \\
\hline Estévia com 60\% rebaudiosídeo (IC5) & $51^{\mathrm{a}}$ & $6,3^{\mathrm{a}}$ \\
\hline Estévia com 80\% rebaudiosídeo (IC6) & $50^{\mathrm{a}}$ & $6,2^{\mathrm{a}}$ \\
\hline Estévia com 95\% rebaudiosídeo (IC7) & $48^{\mathrm{a}}$ & $6,1^{\mathrm{a}}$ \\
\hline Estévia com 97\% rebaudiosídeo (IC8) & $49^{\mathrm{a}}$ & $6,2^{\mathrm{a}}$ \\
\hline
\end{tabular}

*Médias marcadas com letras iguais na mesma linha não diferem significativamente entre si, de acordo com o teste de Tukey $(p>0,05)$. IC1: Sacarose, IC2: Aspartame, IC3: Sucralose, IC4: Neotame, IC5: Estévia 60, IC6: Estévia 80, IC7: Estévia 95, IC8: Estévia 97.

Porém, estes valores encontrados estão bem distintos dos valores observados em sorvetes comercializados, nos quais a porcentagem de ar incorporada chega a 90\% (Cadena \& Bolini, 2013). Os valores são discrepantes devido ao tipo de processamento realizado em ambos, pois, no sorvete comercial, é injetado ar durante a produção dos sorvetes, já nas amostras, a incorporação ocorreu somente por agitação.

\section{$3.6 .2 \mathrm{pH}$}

A análise de $\mathrm{pH}$ realizada nas amostras de sorvete com sacarose e com substitutos de sacarose não evidenciou diferenças entre elas estatisticamente, o que revela que os edulcorantes e as microcápsulas de La-5 não influenciaram no valor de $\mathrm{pH}$ das amostras.

Pazianotti et al. (2010) avaliaram amostras de sorvetes artesanais e comerciais em relação ao pH e estas apresentaram valores de 6,4 e 6,3, respectivamente, que são valores semelhantes aos encontrados no presente estudo, comprovando a estabilidade do $\mathrm{pH}$ das amostras com substituição de sacarose e microcápsulas de La-5.

Ozdemir et al. (2015), em estudo com substituição da sacarose por estévia em sorvetes, também encontraram valores médios de $\mathrm{pH}$ entre 6,5 e 6,2. Com base nesses resultados, é possível verificar que provavelmente a estévia não exerce influência no $\mathrm{pH}$ das amostras.

\subsubsection{Velocidade de derretimento}

A forma de obtenção da formulação de sorvetes pode influenciar o tempo de derretimento, o qual pode ser afetado pela proporção dos sólidos totais, pelo tamanho dos cristais de gelo e pelos tamanhos dos glóbulos de gordura formados. 
O derretimento é uma característica que pode influenciar de forma marcante na qualidade do sorvete (Muse $\&$ Hartel, 2004).

Por esta razão, a análise de ponto de fusão de sorvetes é de grande importância, uma vez que tem relação com a resistência ao derretimento. A análise do ponto de fusão tem como função verificar a resistência ao derretimento do sorvete e consiste em determinar a quantidade de massa que passa por uma determinada peneira, em função do tempo, sob uma temperatura constante de $25^{\circ} \mathrm{C}$ (Marshall et al., 2003).

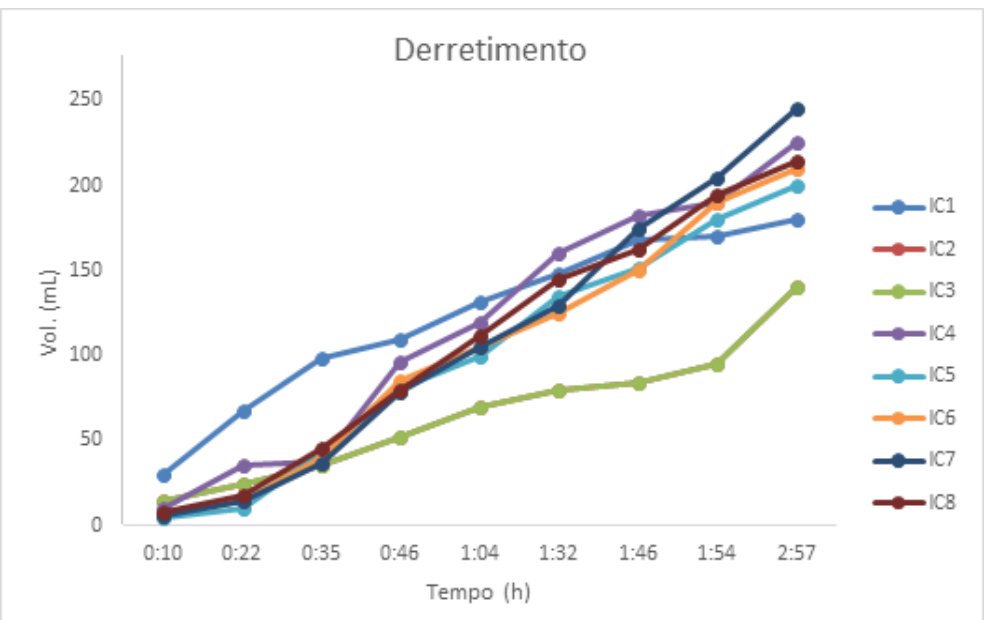

Figura 5. Velocidade de derretimento dos sorvetes em função do tempo (h). IC1: Sacarose. IC2: Aspartame. IC3: Sucralose. IC4: Neotame. IC5: Estévia rebaudiosídeo A 60\%. IC6: Estévia rebaudiosídeo A 80\%. IC7: Estévia rebaudiosídeo A 95\%. IC8: Estévia rebaudiosídeo A 97\%.

Na Figura 5, encontram-se expressos os valores da velocidade do derretimento dos sorvetes em função do tempo. A amostra adoçada com sacarose em sua formulação apresentou velocidade de derretimento maior que os demais sorvetes formulados com inulina e edulcorantes, o que sugere que a utilização da inulina, como agente de corpo, fez com que fosse aumentada a resistência dos sorvetes à fusão. Esses resultados estão em acordo com Beneo (2009), que menciona que a inulina atua aumentando a viscosidade dos produtos, formando gel com a água, e que, em temperaturas mais baixas, este gel é formado mais rapidamente, o que faz com o derretimento do sorvete ocorra mais lentamente.

Da mesma forma, estudos realizados por Góral et al. (2018) com sorvetes probióticos suplementados com inulina em sua formulação mostram que estes apresentaram maior resistência ao derretimento do que os sorvetes sem inulina.

Em razão dos resultados encontrados no presente trabalho, bem como naqueles encontrados por Beneo (2009) e por Góral et al. (2018), é possível indicar que a inulina em sorvete sem sacarose em sua formulação pode proporcionar aumento na cremosidade, provavelmente por haver menores cristais de gelo e menos dureza, promovendo aumento da resistência à fusão dos produtos estudados.

No presente estudo, uma das amostras foi preparada com sacarose e ausência de inulina para haver uma comparação unicamente com o agente adoçante que apresenta o valor referência 1 de doçura (Grenby, 1996).

\section{Conclusão}

De acordo com os resultados obtidos, é possível concluir que a sucralose foi o edulcorante que possibilitou a obtenção de formulação de sorvete de chocolate simbiótico de baixa caloria com doçura equivalente à sacarose, sem diferença significativa em relação ao produto tradicional, conforme o perfil tempo-intensidade múltipla e à aceitação. 
Portanto, foi possível formular um produto para dietas com finalidade especial, com boa aceitação com utilização da sucralose em substituição à sacarose. Com a aplicação da análise tempo-intensidade múltipla, foi possível relacionar a aceitação em função de características sensoriais que ocorrem durante o consumo das amostras analisadas.

As análises de caracterização das amostras revelaram que a substituição da sacarose juntamente com a inulina influenciou na velocidade de derretimento dos sorvetes, em que a amostra com sacarose apresentou derretimento mais rápido do que os demais sorvetes com a presença de inulina na formulação.

\section{Agradecimentos}

À Coordenação de Aperfeiçoamento de Pessoal de Nível Superior (CAPES), pela bolsa de estudos, e ao $\mathrm{CNPq}$, pelo apoio financeiro.

\section{Referências}

American Society for Testing and Materials - ASTM International. (2017). ASTM E1909-13: Standard guide for time-intensity evaluation of sensory attributes. West Conshohocken: ASTM International.

Amerine, M. A., Pangborn, R. M., \& Roessler, E. B. (1965). Principles of sensory evaluation of food (602 p.). New York: Academic Press.

Associação Brasileira das Indústrias e do Setor de Sorvetes - ABIS. (2016). Recuperado em 3 de janeiro de 2017, de http://www.abis.com.br/

Azevedo, Morais-Ferreira, J. M., Luccas, V., \& Bolini, H. M. A. (2017). Bittersweet chocolates containing prebiotic and sweetened with stevia (Stevia rebaudiana Bertoni) with different rebaudioside A contents: Multiple time-intensity analysis and physicochemical characteristics. International Journal of Food Science \& Technology, 52(8), 1731. http://dx.doi.org/10.1111/ijfs. 13470

Beneo. (2009). Benefícios nutricionales de BeneoTM. Mannheim, Germany.

Bolini, H. M. A. (2012, January 3). Time-Intensity Analysis of Flavors and Tastes - TIAFT: software. Registro No. 12445-5. Rio de Janeiro: INPI.

Brasil. Agência Nacional de Vigilância Sanitária - ANVISA. (2005, setembro 23). Regulamento técnico para gelados comestíveis e preparados para gelados comestíveis (Resolução RDC n² 266, de 22 de setembro de 2005). Diário Oficial [da] República Federativa do Brasil, Brasília.

Cadena, R. S., \& Bolini, H. M. A. (2011). Time-intensity analysis and acceptance test for traditional and light vanilla ice cream. Food Research International, 44(3), 677-683. http://dx.doi.org/10.1016/j.foodres.2010.12.012

Cadena, R. S., \& Bolini, H. M. A. (2013). Sorvete sabor creme tradicional e “light": Perfil sensorial e instrumental (Dissertação de mestrado). Faculdade de Engenharia de Alimentos, Universidade Estadual de Campinas, Campinas.

Cardoso, J. M., \& Bolini, H. M. A. (2007). Different sweeteners in peach nectar: Ideal and equivalent sweetness. Food Research International, 40(10), 1249-1253. http://dx.doi.org/10.1016/j.foodres.2007.08.004

Cavallini, D. C. U., \& Bolini, H. M. A. (2005). Sensory profile of mango juice sweetened with different sweeteners and sucrose. Alimentos e Nutrição, 16, 327-336.

Chmiel, T., Kupska, M., Wardencki, W., \& Namiesnik, J. (2017). Application of response surface methodology to optimize solidphase microextraction procedure for chromatographic determination of aroma-active monoterpenes in berries. Food Chemistry, 221, 1041-1056. PMid:27979057. http://dx.doi.org/10.1016/j.foodchem.2016.11.057

Cruz, A. G., Cadena, R. S., Walter, E. H. M., Mortazavian, A. M., Granato, D., Faria, J. A. F., \& Bolini, H. M. A. (2010). Sensory analysis: Relevance for prebiotic, probiotic, and synbiotic product development. Comprehensive Reviews in Food Science and Food Safety, 9(4), 358-373. http://dx.doi.org/10.1111/j.1541-4337.2010.00115.x

Damásio, M. H., \& Costell, E. (1991). Análisis sensorial descriptivo: Generación de descriptores y selección de catadores. Revista Agroquímica Tecnologia Alimentaria, 3(2), 165-178.

Dijksterhuis, G. B., \& Piggott, J. R. (2000). Dynamic methods of sensory analysis. Trends in Food Science \& Technology, 11(8), 284-290. http://dx.doi.org/10.1016/S0924-2244(01)00020-6

Dijksterhuis, G., \& Eilers, P. (1997). Modeling time-intensity curves using prototype curves. Food Quality and Preference, 8(2), 131-140. http://dx.doi.org/10.1016/S0950-3293(96)00039-0

Drake, M. A., \& Gerard, P. D. (2003). Consumer attitudes and acceptability of soy fortified yogurts. Journal of Food Science, 68(3), 1118-1122. http://dx.doi.org/10.1111/j.1365-2621.2003.tb08297.x

Drake, M. A., Truong, V. D., \& Daubert, C. R. (1999). Rheological and sensory properties of reduced-fat processed cheeses containing lecithin. Journal of Food Science, 64(4), 744-747. http://dx.doi.org/10.1111/j.1365-2621.1999.tb15123.x 
Ferraz, J., Gomes da Cruz, A., Cadena, R., Faria, J. A. F., \& Bolini, H. M. A. (2012). Sensory acceptance and survival of probiotic bacteria in ice cream produced with different overrun levels. Journal of Food Science, 77, 524-528. http://dx.doi.org/10.1111/j.1750-3841.2011.02508.x

Ferraz, J. P. (2013). Perfil sensorial descritivo e direcionadores de preferência de sorvete de creme com fruto - oligossacarídeo e diferentes edulcorantes (Dissertação de mestrado). Faculdade de Engenharia de Alimentos, Universidade Estadual de Campinas, Campinas.

Gibson, G. R., \& Roberfroid, M. B. (1995). Dietary modulation of the human colonic microbiota: Introducing the concept of prebiotics. The Journal of Nutrition, 125(6), 1401-1412. PMid:7782892. http://dx.doi.org/10.1093/jn/125.6.1401

Gibson, G. R., Hutkins, R., Sanders, M. E., Prescott, S. L., Reimer, R. A., Salminen, S. J., Scott, K., Stanton, C., Swanson, K. S., Cani, P. D., Verbeke, K., \& Reid, G. (2017). Expert consensus document: the international scientific association for probiotics and prebiotics (ISAPP) consensus statement on the denifition and scope of prebiotics. Nature Reviews. Gastroenterology \& Hepatology, 14(8), 491-502. http://dx.doi.org/10.1038/nrgastro.2017.75

Giri, A., Ramachandra, H. G., \& Ramesh, V. (2012). Effect of incorporating whey protein concentrate into stevia-sweetened Kulfi on physicochemical and sensory properties. International Journal of Dairy Technology, 66(2), 286-290.

http://dx.doi.org/10.1111/1471-0307.12005

Góral, M., Kozlowicz, K., Pankiewicz, U., \& Góral, D. (2018). Magnesium enriched lactic acid bactéria as a carrier for probiotic ice cream production. Food Chemistry, 239, 1151-1159. PMid:28873534. http://dx.doi.org/10.1016/j.foodchem.2017.07.053

Goto, A., \& Clemente, E. (1998). Influência do rebaudiosídeo A na solubilidade e no sabor do esteviosídeo. Food Science and Technology, 18(1), 3-6. http://dx.doi.org/10.1590/S0101-20611998000100002

Grenby, T. H. (Ed.). (1996) Advances in sweeteners (303 p.). London: Blackie Academic \& Professional. http://dx.doi.org/10.1007/978-1-4613-1229-1.

Guinard, J.-X., Zoumas-Morse, C., Mori, L., Uatoni, B., Panyam, D., \& Kilara, A. (1997). Sugar and fat effects on sensory properties of ice cream. Journal of Food Science, 62(5), 1087-1094. http://dx.doi.org/10.1111/j.1365-2621.1997.tb15044.x Instituto de Laticínios Cândido Tostes - ILCT. (2002). Fundamentos básicos da tecnologia de queijos. Juiz de Fora: Epamig. Lawless, H. T., \& Heymann, H. (2010). Sensory evaluation of food: Principles and practices (2nd ed.). New York: Springer. http://dx.doi.org/10.1007/978-1-4419-6488-5.

Marshall, R. T., Goff, H. D., \& Hartel, R. W. (2003). Ice cream (216 p., 6th ed.). New York: Springer. http://dx.doi.org/10.1007/978-1-4615-0163-3.

Meilgaard, M., Civille, G., \& Carr, T. (2007). Sensory evaluation techniques (387 p.). Boca Raton: CRC Press.

Mello, L. L. M. M., Childs, J., Drake, M. A., Bolini, H. M. A., \& Efraim, P. (2010). Expectations and acceptability of diabetic and reduced calorie milk chocolates among non-diabetics and diabetics in the USA. Journal of Sensory Studies, 23, 1-20.

Melo, L. L. M. M., Bolini, H. M. A., \& Efraim, P. (2009). Sensory profile, acceptability, and their relationship for diabetic/reduced calorie chocolates. Food Quality and Preference, 20(2), 138-143. http://dx.doi.org/10.1016/j.foodqual.2008.09.001

Mintel. (2015). China replaces us as world's largest ice cream market. Recuperado em 3 de janeiro de 2017, de http://www.mintel.com/press-centre/food-and-drink/china-replaces-us-as-worlds-largest-ice-cream-market

Morais, E. C., Cruz, A. G., \& Bolini, M. A. (2013). Gluten-free bread: Multiple time-intensity analysis, physical characterization and acceptance test. International Journal of Food Science \& Technology, 48, 2176-2184. http://dx.doi.org/10.1111/ijfs.12202

Morais, E. C., Pinheiro, A. C. M., Nunes, C. A., \& Bolini, H. M. A. (2014). Multiple time-intensity analysis and temporal dominance of sensations of chocolate dairy dessert using prebiotic and different high-intensity sweeteners. Journal of Sensory Studies, 29(5), 339-350. http://dx.doi.org/10.1111/joss.12115

Mosquim, M. C. A. (1999). Fabricando sorvetes com qualidade. São Paulo: Fonte Comunicações e Editora Ltda.

Muse, M. R., \& Hartel, R. W. (2004). Ice cream structural elements that affect melting rate and hardness. Journal of Dairy Science, 87(1), 1-10. PMid:14765804. http://dx.doi.org/10.3168/jds.S0022-0302(04)73135-5

Nofre, C., \& Tintil, J. M. (2000). Neotame, discovery, properties, utillity. Food Chemistry, 69(3), 245-257. http://dx.doi.org/10.1016/S0308-8146(99)00254-X

Overbosch, P. A. (1986). Theoretical model for perceived intensity in human taste and smell as a function of time. Chemical Senses, 11(3), 315-329. http://dx.doi.org/10.1093/chemse/11.3.315

Ozdemir, C., Arslaner, S., Ozdemir, S., \& Allahyari, M. (2015). The production of ice cream using stevia as a sweetener. Journal of Food Science and Technology, 52(11), C7545-C7548. http://dx.doi.org/10.1007/s13197-015-1784-5

Palazzo, A. B., \& Bolini, H. M. A. (2009). Multiple time-intensity analysis and acceptance of raspberry-flavored gelatin. Journal of Sensory Studies, 24(5), 648-663. http://dx.doi.org/10.1111/j.1745-459X.2009.00231.x

Palazzo, A. B., \& Bolini, H. M. A. (2013) Avanços no estudo de edulcorantes em chocolates tipo ao leite, light em calorias e isentos de lactose e sacarose: Perfil sensorial descritivo, tempo-intensidade múltiplo e vida útil (Tese de doutorado). Faculdade de Engenharia de Alimentos, Universidade Estadual de Campinas, Campinas.

Park, K. J., \& Antonio, G. C. (2006). Análises de materiais biológicos. Campinas: Universidade Estadual de Campinas, Faculdade de Engenharia Agrícola.

Pazianotti, L., Bosso, A. A., Cardoso, S., Costa, M. R., \& Sivieri, K. (2010). Características microbiológicas e físico-químicas de sorvetes artesanais e industriais comercializados na região de Arapongas-PR. Revista do Instituto Laticinio. Cândido Tostes, 65(377), 15-20. 
Sorvetes de chocolate simbiótico de baixa caloria: análise tempo-intensidade múltipla e estudo de preferência

Peres, J. F., \& Bolini, H. M. A.

Peres, J. F. (2018) Sensory profile, influence of information in the acceptance analysis and preference directors in light synbiotic chocolate ice cream with different high-intensity sweeteners (Tese de doutorado). Faculdade de Engenharia de Alimentos, Universidade Estadual de Campinas, Campinas.

Sanders, M. E., \& Marco, M. L. (2010). Food formats for effective delivery of probiotics. Annual Review of Food Science and Technology, 1(1), 65-85. PMid:22129330. http://dx.doi.org/10.1146/annurev.food.080708.100743

Statistical Analysis System (2012). SAS for Windows Version 9.1.3 Service Pack 3. Cary, NC: SAS Institute, Inc.

Stone, H., \& Sidel, J. (2003). Sensory evaluation practices (377 p.). New York: Academic Press.

Umbelino, D. C. (2005). Caracterização por análise descritiva quantitativa e análise tempo-intensidade de suco e de polpa de Manga (Mangifera indica L.) adoçados com diferentes edulcorantes (Tese de doutorado). Faculdade de Engenharia de Alimentos, Universidade Estadual de Campinas, Campinas.

Wakeling, I. N., \& MacFie, H. J. H. (1995). Designing consumer trials balanced for first and higher orders of carry-over effect when only a subset of k samples from t may be tested. Food Quality and Preference, 6(4), 299-308.

http://dx.doi.org/10.1016/0950-3293(95)00032-1

Financiamento: Ministério da Ciência, Tecnologia e Inovação > Conselho Nacional de Desenvolvimento Científico e Tecnológico; Coordenação de Aperfeiçoamento de Pessoal de Nível Superior. 